\title{
Individual-Typological Approach to the Assessment of Adaptation, Health and Psychophysiological Indicators of School Students Doing Sports
}

\author{
Filippova S.N. ${ }^{1 *}$ Gorrelik V.V. ${ }^{2}$ Belyaev V.S. ${ }^{3}$ Knysheva T.P. ${ }^{4}$ \\ ${ }^{1}$ Russian State Social University, Klin, Russia \\ ${ }^{2}$ Department of Adaptive Physical Education, Sports and Tourism, Institute of Physical Education and Sports \\ Togliatti State University, Tolyatti, Russia \\ ${ }^{3}$ Institute of Natural Science and Sports Technology, Department of Adaptology and Sports Training, Moscow \\ Pedagogical University, Moscow, Russia \\ ${ }^{4}$ Eureka Intellectual Development Center, Tolyatti, Russia \\ *Corresponding author.Email: svetjar@mail.ru
}

\begin{abstract}
The paper is devoted to experimental justification of widespread application of individualization in choosing types and volumes of physical activity for physical education classes taking into account typological indicators. The purpose of the study was to improve the physical education of schoolchildren by developing the concept of individual-typological approach to assessing the regulation of functional systems of the body for the educational process management. Materials and methods: theoretical review of the current scientific literature on the issues allowed forming the methodology of the experimental study. The computer program Express Assessment of Physical Health $(F H)$ and Development $(F D)$ of Schoolchildren was used as diagnostic methods, alongside with the measurement of Quetelet, Robinson, Skibinsky, Shapovalova, Ruffier indices. In order to assess the efficiency of FE classes in the main group (MG) (experimental) and comparison group (CG) (control), heart rate variability (HRV) indicators were detected through electrocardiogram characteristics (ECG) using Varikard 2.51 hardware and software complex. The system of selection of loads at physical education classes based on typological indicators of regulation of muscular and cardio-respiratory systems was developed and tested. Mathematical and statistical processing of data was carried out by means of $\lambda$-Kolmogorsk-Smirnov one-sample test, $\chi^{2}$ Pearson's parametric criterion and k-means clustering (Euclidean distance). The results of the study showed the efficiency of using individual health set of exercises to minimize functional deviations of body systems according to PD and HRV.
\end{abstract}

Keywords: physical health, adaptation, school student, heart rate variability

\section{INTRODUCTION}

The increased attention of scientists and teachers to the problems of children's health is caused by the negative trends in its change and deterioration of the demographic situation in the Russian Federation. The health of the young generation is becoming the most citical social priority of a family, educational institutions and the state. In addition to statistics on the incidence of children and young people in the Russian Federation [1, 2, 12], the results of the Ready for Labor and Defense standards (GTO), which only $5-10 \%$ of schoolchildren and students were able to pass, served a relevant confirmation of the low level of health [6].

The consideration of genotypic, ontogenetic, functional-physiological and socio-cultural levels of health shows that the ontogenetic level is the most controlled and manageable for the development of individual health of children. Its sufficient indicators for normal life activity are ensured by favorable conditions and lifestyle, as well as minimization of unfavorable (pathogenic) risk factors.

Individual development - ontogenesis is the realization of individual genotype of a person in its interaction with specific conditions of vital activity under the influence of which an individual phenotype is formed.

In order to manage the health of children, it is necessary to conduct an in-depth and detailed study of the health-to-disease transition of prenosological and borderline conditions of children in order to ensure preventive and corrective effects by various health improvement measures, the leading of which is physical education (PE).

The physiological basis of prenosological conditions is the depletion of human psychophysical abilities for full adaptation and reduction of its reserves under total increased loads of schoolchildren in the educational environment of educational institutions (EI), family and social setback $[3,5,10]$. 
Creation of modern digital IT-diagnostic methods at EI on the basis of mathematical analysis of heart rate variability (HRV) allows registering the regulatory effects on cardiovascular system, levels of health and adaptation of schoolchildren $[3,4,9,15]$.

It shall be stressed that new instrumental methods opens previously not available opportunities to know the CVS functions, which generalizes its influence on the whole organism and projects regulatory effects on its various functional systems.

In a number of works it is shown $[14,15]$ that the CVS has a multilevel system of external regulation, which allows the autonomously controlled cardiosystem to change the parameters of functioning and adapt to physical loads and environmental effects. The CVS regulation system includes the following: 1) the effect of the CNS, the brain and its cortex; 2) reciprocal regulatory effects of the parasympathetic system activating sympathetic and restraining CVS activity; 3) synergistic (mixed) effects of CVS and VNS; 4) autonomous system of heart contractility regulation. Registration and tracking of the dynamics of these regulatory influences via screening and monitoring is a priority in the concept of new physical education at schools and universities $[3,5]$.

The studies showed that the identified neurophysiological and neurovegetative types of regulation in stable, familiar environment conditions at rest are stable characteristics of children, which their individualtypological response to loads and environmental effects depends on. They also determine the level of health and adaptation of the body. Thus, researchers have developed the assessment method using a set of HRV parameters, which allows studying individual-typological "portrait" of regulatory systems, adaptation and health of a child, taking into account his strengths and weaknesses, restrictions and ensuring individualized impacts by means and methods of physical education $[3,5,10,13]$.

However, there is currently insufficient experimental evidence of a close link between the typological properties of neurovegetative regulatory systems and the efficiency of the effects of motor loads during PE classes on children. This work is devoted to the study of this problem.

The purpose of the study is to improve the physical education of schoolchildren by developing the concept of an individual-typological approach to assessing the regulation of functional systems of the body for the management of the educational process.

Research objectives:

1. To evaluate the set of PH and HRV parameters, which allow exploring the individual-typological "portrait" of regulatory systems, adaptation and health of a child, taking into account his strengths and weaknesses, restrictions and ensuring individualized impacts by means and methods of physical education.

2. To develop and test the system of selection of loads during PE classes on the basis of typological indicators of neurophysiological regulation of muscular and cardiorespiratory systems.

3. To determine the impact of the volume of physical loads on the functional status of students giving the maximum health thus promoting physical education of schoolchildren.

\section{METHODS AND MATERIALS}

The automated computer program Express Assessment of the Physical Health of Schoolchildren was used for the express assessment of PD and health. The diagnostics of physical development (IPD) is carried out by known indices: Quetelet (QI), Robinson (RI), Skibinsky (SI), Shapovalova (ShI), Ruffier (RI). In order to calculate the indices of the automated computer program the functional indicators were measured according to the given formulas and motor tests were carried out [8].

For HRV analysis, the Varikard 2.51hardware and software complex was used, which makes it possible to calculate up to 40 different parameters recommended by both Russian and European-American standards [9].

The study was conducted over 2013-2016 and involved three stages. The contingent included school student of the 5 th grade (20 boys, 10-11 years old) of school No. 90 of Togliatti, who made up the main group (MG) and engaged in PE under the correction and development program. The school students of the 5th grade (20 boys, 10-11 years old) of school No. 5 of Togliatti constituting the comparison group (CG) were studying according to the standard school program for the 5 th grade.

Stage I (2013-2015): ascertaining pedagogical experiment (PE), measurement of initial IPD and health, HRV.

Stage II (2013-2015): forming PE. Individualized physiologically based motor loads and healthy lifestyle recommendations selected on the basis of individual IPD and children's health were used as forming effects on MG students.

Stage III (2016): processing and analysis of PE data. The developed medical and biological technologies were used in the educational process of other secondary EI of Togliatti.

Based on PD indices, health and HRV data, the PE Correction and Health Program was developed, which served the basis for effects at PE forming stage for adaptation and health of children. Schoolchildren with deviation relative to the norm indices of PD and health were assigned to risk groups and were subjected to PE classes using physiologically justified correction and health load at PE classes, depending on disorders in a certain functional system of the organism (CVS, respiratory, muscular) determined via health indices $[3,8]$.

Statistical data processing. Mathematical and statistical processing of results was carried out using SPSS 17.0. statistical program for Windows. The $\lambda$-KolmogorskSmirnov one-sample test revealed the normality of distribution parameters, which in the future allowed determining the choice of statistical methods of data processing. In order to detect differences in the comparison of empirical distributions of health indices, cardiorespiratory and psychophysiological indices at the beginning and at the end of the study, the $\chi 2$ Pearson's parametric criterion was used. The reliability of statistical 
significance was defined at the level of $\mathrm{p} \leq 0.05(*), \mathrm{p} \leq 0.01$ $(* *)$ at freedom degree $\mathrm{v}=\mathrm{k}-1=19$, where $\mathrm{k}=20$ (number of school students in MG and CG). The use of k-means clustering provided for further construction of the Euclidean distance model for the given clusters (types of regulation), relative to the centroid of optimal values at the beginning and at the end of the study.

\section{RESULTS}

During the HRV study and on the basis of the obtained data, typologies of schoolchildren by levels of nervousvegetative regulation (NVR) of CVS functions detected by the body's reaction to motor loads were determined. The typology was carried out according to the N.I. Schlyk's classification [15]. In total, 4 types of regulation were identified, which were characterized by cardiosystem functions control, presented in Table 1.

Physiologically sound load was used at physical education (PE) classes taking into account types of neurophysiological and vegetative regulation of students.

Table 1 Typology of human nervous-vegetative regulation
Figure 1 shows the distribution of cardiorespiratory indicators in schoolchildren depending on the type of CVS regulation.

Children with III type of CVS regulation demonstrate the improvement in adaptation to physical loads, as evidenced by the values of vegetative HRV indicators, integral indices of physical development and health, psychophysiological indicators, unlike children with I, II, IV type of HRV regulation.

It was established that in students with III type of HRV the parameters of integral indices of physical development and health have optimal values (are in the optimal sphere) of statokinesiogram, unlike students with I, II and IV type of HRV. Schoolchildren with III type of HRV show the smallest variation in the cardiorespiratory system (CRS). Minimization of CRS variation can indicate functional stability and sufficient adaptation reserves, stability of integrative mechanisms of cardiorespiratory megasystem to external disturbance effects in the form of motor loads during PE classes.

\begin{tabular}{|l|l|l|l|}
\hline \multicolumn{4}{|c|}{ Types of human nervous-vegetative regulation } \\
\hline \multicolumn{1}{|c|}{ I type } & \multicolumn{1}{|c|}{ II type } & \multicolumn{1}{c|}{ III type } & \multicolumn{1}{c|}{ IV type } \\
\hline $\begin{array}{l}\text { MPCR: moderate } \\
\text { prevalence of central } \\
\text { and sympathetic } \\
\text { regulation of CVS } \\
\text { rate. }\end{array}$ & $\begin{array}{l}\text { PPCR: pronounced } \\
\text { prevalence of central and } \\
\text { sympathetic regulation of } \\
\text { CVS rate. Pronounced } \\
\text { prevalence of central over } \\
\text { autonomous. }\end{array}$ & $\begin{array}{l}\text { MPAR: moderate } \\
\text { prevalence of autonomous } \\
\text { regulation, } \\
\text { parasympathetic activity. } \\
\text { Optimal state of } \\
\text { regulatory systems and } \\
\text { training. }\end{array}$ & $\begin{array}{l}\text { PPAR: pronounced prevalence of } \\
\text { autonomous regulation. } \\
\text { Pronounced prevalence of } \\
\text { parasympathetic VNS activity } \\
\text { over the sympathetic one in CVS } \\
\text { regulation. }\end{array}$ \\
\hline
\end{tabular}
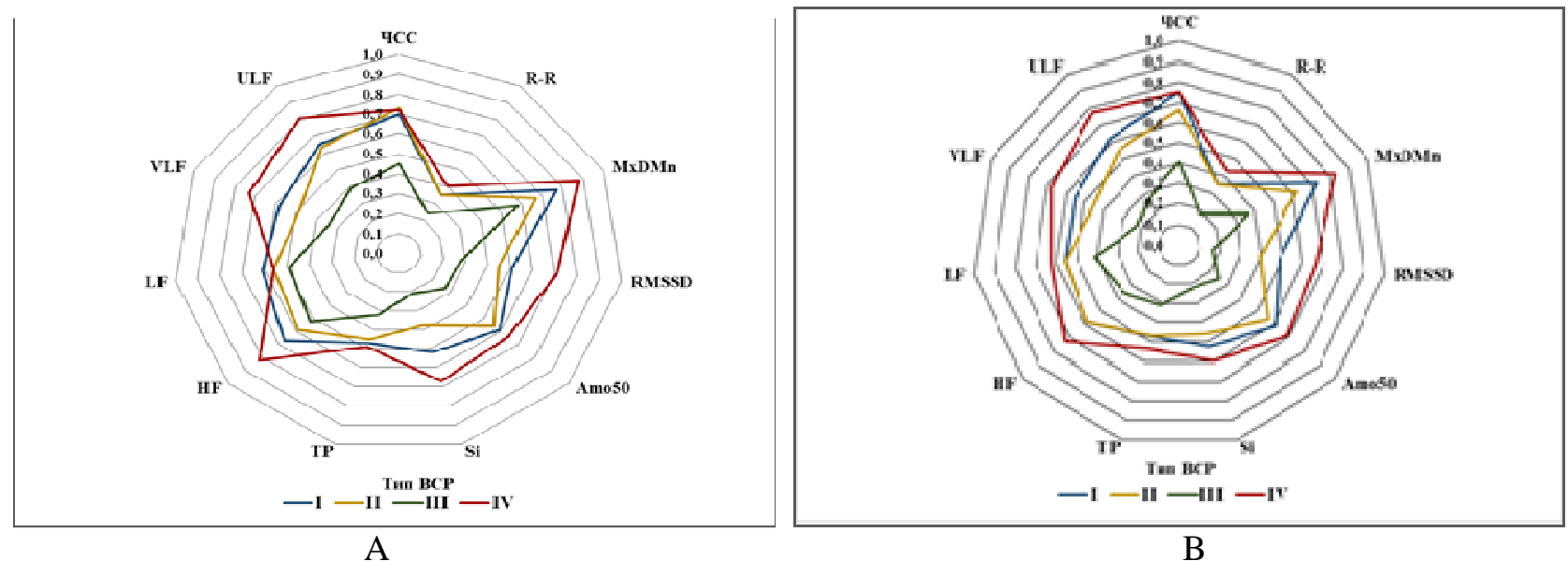

Figure 1 Distribution of cardiorespiratory indicators (I, II, III, IV type HRV) at the beginning (A) and at the end of the study (B) in statokinesiogram (optimal domain) in the MG. 


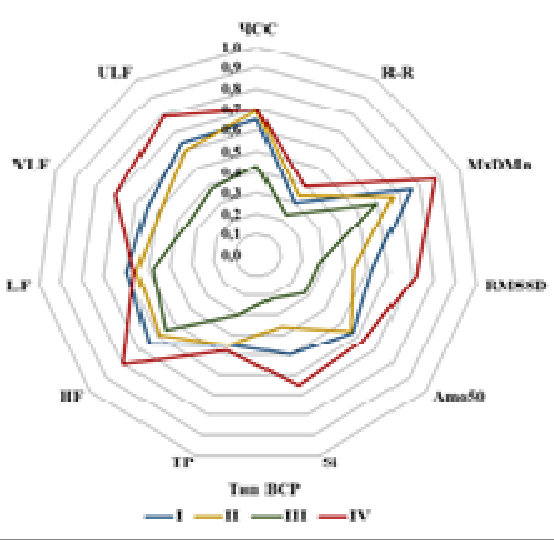

A

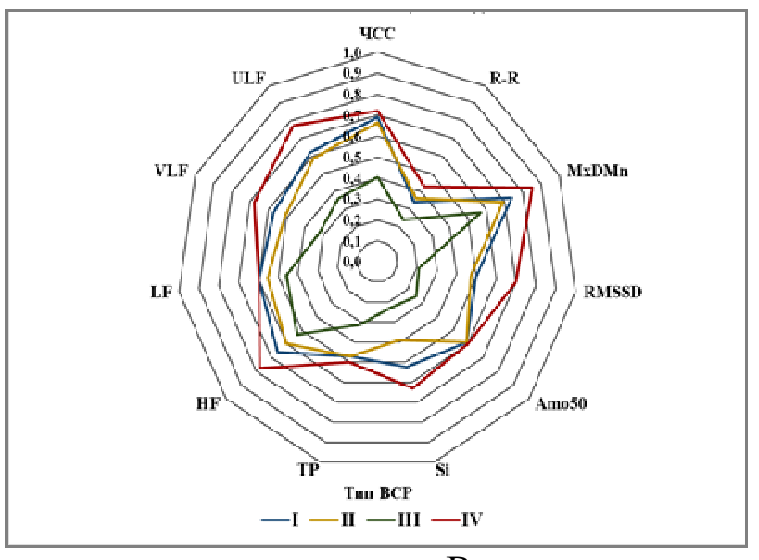

B

Figure 2 Distribution of cardiorespiratory indicators (I, II, III, IV type HRV) at the beginning (A) and at the end of the study (B) in statokinesiogram (optimal domain) in the CG.

At the same time, schoolchildren with other types of CVS regulation show an increase in parameters in a number of types: (II-I), IV. With the similarity of CRS indicators of II and I types the expressed differences of CRS values are observed in extreme regulatory IV and III types. The maximization of CRS variability in children with IV type of CVS regulation can indicate expressed sensitivity and increased reactivity of the body to external motor loads, which demonstrates the reduction of adaptation abilities, endurance and tolerance of motor loads. The asymmetric regulatory types identified by Schlyk N.I. [14] are formed through the interaction with the environment on a genetic basis and have uneven distribution in the sampling of children's population of the Russian Federation. Therefore, similarly to somatic types of constitution [7, 11], it may be considered that I-IV types of CVS regulation represent variants of the regulatory constitution, along with private constitutions (hormonal, metabolic, psychological).

Modern constitutiology is becoming a field of interdisciplinary integrative research, not just part of physical anthropology. Therefore, when identifying a new private regulatory constitution, we face wide possibilities to explore individual-typological regulatory characteristics in different age groups in close cooperation with other identified constitutional types, especially well-studied somatic and psychological constitutions [7, 11]. The results will be demanded in pedagogy, medicine, physical education and sports.

Table 2 Reliability of differences in comparison of empirical distributions of cardiorespiratory indicators at the beginning and at the end of the study in MG/CG received at the level of $\mathrm{p} \leq 0.05$ (*), $\mathrm{p} \leq 0.01$ (**) at freedom degree $v=\mathrm{k}-1=19$ via $\chi^{2}$ Pearson's parametric criterion.

\begin{tabular}{|l|l|l|l|l|}
\hline \multirow{2}{*}{ HRV indicator } & \multicolumn{2}{c|}{ II I } & \multicolumn{1}{c|}{ III } & IV \\
\cline { 2 - 5 } & \multicolumn{1}{|c|}{ I } & & \\
\hline Heart rate & $29.7 / 28.8$ & $33.0 * / 30.1$ & $34.1 * / 30.1$ & $29.8 / 29.7$ \\
\hline R-R & $28.1 / 28.7$ & $27.48 / 28.1$ & $36.2 * * / 29.6$ & $28.7 / 28.4$ \\
\hline MxDMn & $28.9 / 29.0$ & $29.7 / 28.7$ & $37.2 * * / 27.5$ & $23.4 / 25.1$ \\
\hline RMSSD & $29.1 / 28.5$ & $30.0 / 29.8$ & $36.9 * * / 29.1$ & $30.1 / 30.1$ \\
\hline Amo50 & $30.0 / 29.1$ & $29.1 / 28.1$ & $30.1 / 28.5$ & $30.2 * / 29.7$ \\
\hline Si & $29.7 / 29.8$ & $35.2 * / 30.1$ & $29.8 / 28.4$ & $34.7 * / 28.5$ \\
\hline TP & $30.0 / 29.9$ & $29.7 / 28.6$ & $29.5 / 29.1$ & $29.4 / 29.8$ \\
\hline HF & $36.2 * * / 30$ & $30.1 / 29.1$ & $37.5 * * / 29.1$ & $36.3 * * / 29.9$ \\
\hline LF & $30.0 / 30.0$ & $30.1 / 29.4$ & $36.2 * * / 30.0$ & $35.4 * / 28.7$ \\
\hline VLF & $29.9 / 28.6$ & $30.1 / 28.5$ & $37.8 * * / 28.1$ & $36.3 * * / 28.5$ \\
\hline ULF & $30.0 / 29.5$ & $30.2 * / 29.8$ & $38.1 * * / 29.4$ & $29.8 / 27.3$ \\
\hline
\end{tabular}




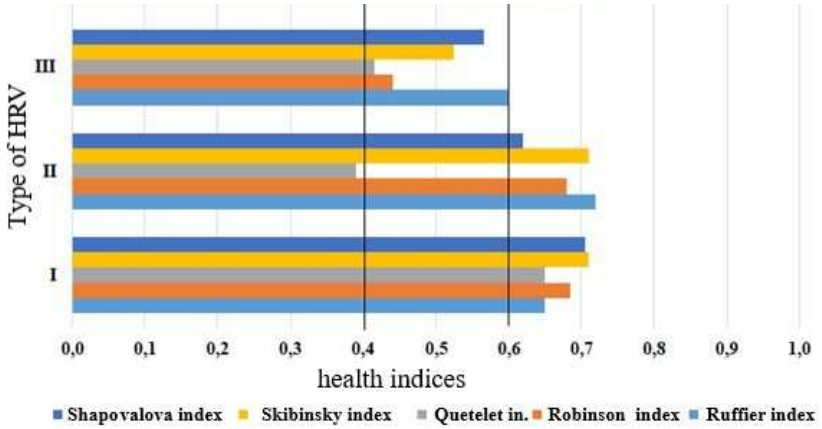

A

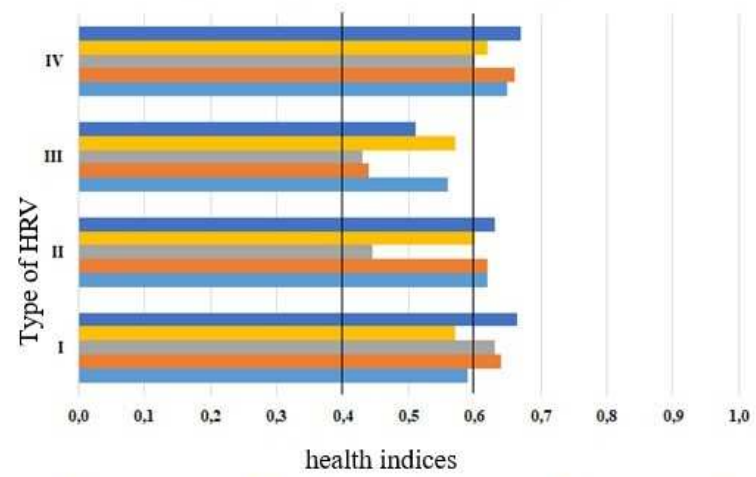

- Shapovalova index $=$ Skibinsky index $=$ Quetelet in. $\mid$ Robinson index $\|$ Ruffier in. B

Figure 3 Distribution of health indices in schoolchildren with I, II, III, IV type of HRV at the beginning (A) and at the end (B) of the study in statokinesiogram (optimal sphere) in MG.

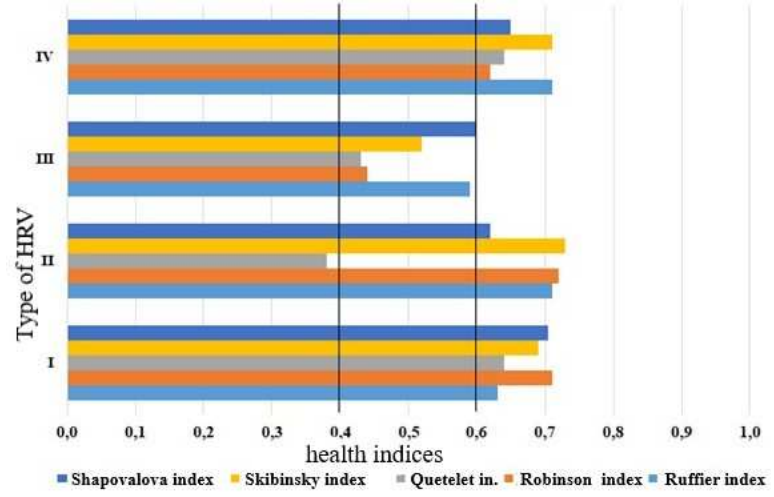

A

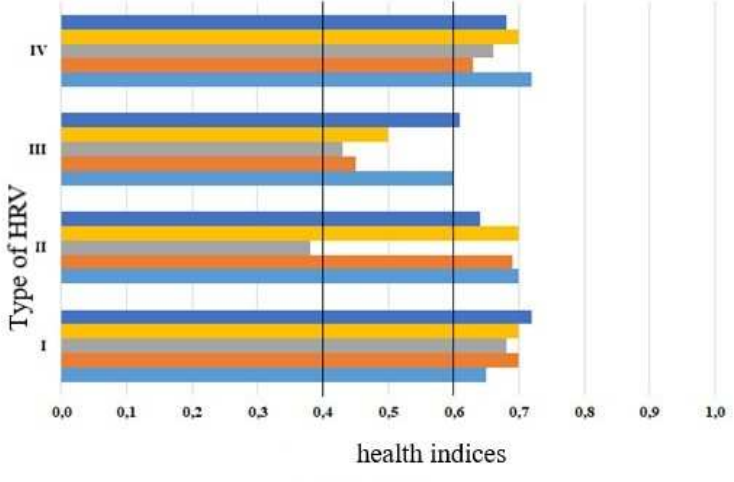

"Shapovalova index $=$ Skibinsky index $=$ Quetelet in. $=$ Robinson index $=$ Ruffier in.

B

Figure 4 Distribution of health indices in schoolchildren with I, II, III, IV type of HRV at the beginning (A) and at the end (B) of the study in statokinesiogram (optimal sphere) in CG

Table 3 Reliability of differences in comparison of empirical distributions of health indices at the beginning and at the end of the study in MG/CG received at the level of $\mathrm{p} \leq 0.05(*), \mathrm{p} \leq 0.01(* *)$ at freedom degree $v=\mathrm{k}-1=19$ via $\chi^{2}$ Pearson's parametric criterion.

\begin{tabular}{|l|c|c|c|c|}
\hline \multirow{2}{*}{ ED } & \multicolumn{4}{|c|}{ HRV type } \\
\cline { 2 - 5 } & I & II & III & $36.1 * / 28.7$ \\
\hline Shapovalova index & $29.1 / 29.7$ & $30.0 / 29.9$ & $30.0 / 29.4$ & $38.0 * * / 28.7$ \\
\hline Skibinsky index & $36.1 * * / 30.1$ & $36.4 * * / 30.1$ & $30.0 / 29.6$ & $39.4 * * / 28.2$ \\
\hline Quetelet index & $29.9 / 28.4$ & $30.1 * / 29.6$ & $29.9 / 28.1$ & $30.2 * / 29.7$ \\
\hline Robinson index & $30.0 / 29.7$ & $30.1 * / 29.4$ & $36.1 * / 28.2$ & $40.0 * * / 29.1$ \\
\hline Ruffier index & $30.1 * / 30.0$ & $38.1 * * / 30.0$ & & \\
\hline
\end{tabular}

Consideration of ED changes in students depending on individual-typological status shows that ED variation and values in the group of children with III type of HRV under the action of physiologically justified motor load were stabilized, their distribution decreased. The Shapovalova index (speed-strength endurance of back and abdomen muscles) and the Ruffier index (CVS reaction to loads) showed expressed positive dynamics. The distribution of 
indices in the groups of I, II type decreased moderately, and in type IV it increased significantly. These data show a decrease in tolerance to motor load, especially in schoolchildren with IV type of CVS regulation.

Consequently, the type of neurophysiological regulation of CVS functions and the whole organism is the most important physiological indicator determining the functioning of the human body. The regulation type as a phenotypic feature is formed under the influence of environmental factors, including motor activity. Individual-typological characteristics also depend on the

Table 4 Comparison of sensory and sensomotor responses in schoolchildren with different types of NVR in MG and $\mathrm{CG}$ compared to the normative values at the control stage of the pedagogical experiment $(\mathrm{M} \pm \mathrm{m})$

\begin{tabular}{|l|c|c|c|c|}
\hline \multirow{2}{*}{ Studied variables } & \multicolumn{3}{c|}{ HRV type, MG/CG MG/CG, M \pm m } \\
\cline { 2 - 5 } & I & II & III & IV \\
\hline Time of simple sensomotor reaction to color & $30.0 / 30.1$ & $31.1 * / 30.0$ & $26.7 / 27.1$ & $36.2 / 29.1^{* *}$ \\
\hline Making time of a color square in random place & $29.0 \pm 0.01 / 30.0 \pm 0.01$ & $30.15^{*} / 28.0$ & $27.03 / 25.4$ & $38.0 / 28.1^{* *}$ \\
\hline Color discrimination in screen field & $28.7 / 30.7$ & $31.1 * / 25.2$ & $26.3 / 30.0$ & $39.5^{* * / 30.3 * *}$ \\
\hline Discrimination of even numbers & $29.0 / 30.0$ & $27.1 / 30.1$ & $29.3 / 28.5$ & $32.1 / 30.1^{*}$ \\
\hline Data processing speed & $29.1 / 28.9$ & $28.1 / 29.0$ & $29.1 / 27.8$ & $30.1 / 29.4 *$ \\
\hline Work performance speed & $27.2 / 29.7$ & $27.4 / 28.9$ & $28.2 / 29.1$ & $28.6 / 28.4^{*}$ \\
\hline
\end{tabular}

$*-\mathrm{P}<0.05$ changes are reliable relative to the norm.

$* *-\mathrm{P}<0.01$ changes are reliable relative to the norm.

The analysis of data of sensomotor response measurements presented in Figure 3 shows that the schoolchildren with III type of NVR demonstrate the most stable, within the limits of norm, sensomotor response to physical loads. Sensomotor responses of students with I and II types of regulation shifted from normal status under the influence of physical activity to advanced response, and in students with IV type of NVR the delayed response to irritant normalized after PE classes. Similar patterns are observed when the modality of the sensory stimulus changes (Fig. 3, B).

The data (Fig. 4) on the function of discrimination of color and verbal images by schoolchildren of different constitutional types of regulation showed that the response of children with III type of NVR regulation is stabilized, remains within the limits of the norm after physical activity.

A small advanced response in children of the I, II type of NVR after load normalizes. The most unfavorable increase in response time by $30 \%$ under the influence of physical activity was shown by schoolchildren with IV type of NVR. This indicates the effect of increased reactivity of regulatory mechanisms of the cardiosystem, their destabilization in case of motor activity impact on visual sensory perception. state of nervous, CVS, respiratory and other functional systems of the body, which change in ontogenesis under the influence of physical and mental activity.

In order to determine the relationship between the types of regulatory constitution and sensory reactions, the study of sensomotor indicators in schoolchildren with different types of NVR was carried out. The performance of students' academic work depends on their sensory status, perception and processing of information. The results are shown in Table 4. 
typical for IV type of NVR does not lead to optimal formation of adaptive state of organism and visual sensory processes of perception and processing of information under conditions of motor and educational loads. The selection of effective and safe physical activity during PE classes on the basis of indices of physical development and control of its influence using individual-typological approaches will provide a new paradigm of development of physical education of schoolchildren $[3,5,10]$.

Thus, the studies show that the chosen orientation of physical education for 7-8 year-old sportswomen is correct and gives an increase in efficiency of motor actions of figure skater. The application of psychophysiological analysis of training effects is particularly justified in children and adolescents, which makes it possible to include the most effective elements developing the motor qualities and abilities necessary at this age stage of active growth and dynamic development into the program of training classes.

\section{SUMMARY}

1. The effect of the set of factors of the educational environment on schoolchildren leads to a decrease in their adaptation and health indicators.

2. Classes under the standard current programs of school-based PE do not prevent deterioration of health and reduction of adaptation potential of schoolchildren in the process of education.

3. Based on the analysis of the value of gradation of types of HRV regulation, the need to highlight a new private constitution such as the "regulatory constitution" and the need to study its individual-typological characteristics in interaction with other private constitutions, especially somatic and psychological ones, is justified.

4. The relationship of types of NVR and sensomotor and sensory processes of visual analyzer is determined. In schoolchildren with the III type of HRV regulation of cardiorespiratory indicators and ED are stable, and in children with the IV type of CVS regulation under the influence of physical activity show increased reactivity, and processes of recognition of visual information are slowed down by $30 \%$. In schoolchildren with I and II types the situation is intermediate between extreme types.

5. The field of practical application of the concept of regulatory constitution was defined. On the basis of digital technologies, using methods of screening and monitoring of its types, it is possible to determine the values of motor loads during PE classes, forms, methods, tools for improvement of efficiency and safety of physical education at secondary EI.

\section{REFERENCES}

[1] N.A. Agazhanyan, R.M. Baevsky, Teaching on health and adaptation problems, RUDN Publishing House, Moscow, 2006, 284 p.
[2] D.N. Gavrilov, D.N. Pukhov, Results of the study of health and behavior of school children, Preventive and clinical med. 2(51) (2014) 32-34.

[3] V.V. Gorelik, S.N. Filippova, New physical education at school: corrective and health-improving use of physiological indicators of students as markers of physical development and health disorders, Person. Sport. Med. 19(1) (2019) 42-49. DOI: 10.14529/hsm190106

[4] D.V. Zakharchenko, V.B. Dorokhov, V.I. Torshin et al., Method of non-invasive diagnosis of violations of functional condition of an operator on the basis of analysis of target tracking smoothness, vol. 43, no. 2 , 2017, pp. 74-81.

[5] L.N. Igisheva, E.M. Kazin, A.R. Galeev, Influence of moderate physical activity on heart rate variability in children of primary and secondary school age, Human physiol. 3 (2006) 55-61.

[6] R.Kh. Matrichenko, Students compliance with the standards of testing of the "Ready for Labor and Defense" complex, Topical problems of physical education and sports at a university, Materials of the All-Russian scientific methodical conference (Gubkin Russian State Univer. of Oil and Gas, 30 January -1 February 2019), pp. 116-118.

[7] T.V. Panasyuk, Formation of human somatotype in prepubertal period and its influence on the growth, Materials of the conference: Anthropology on the threshold of the 3rd millennium, vol. 2, 2003, pp. 644-652.

[8] S.D. Polyakov, S.V. Khrushchev, A.M. Sobolev, Computer technologies for monitoring of physical health of schoolchildren, Moscow, 2002, pp. 1-11.

[9] Yu.N. Semenov, R.M. Baevsky, Varikard hardware and software complex to assess the functional state of organism according to results of mathematical analysis of heart rhythm, Heart rate variability, Izhevsk, 1996, pp. 160-162.

[10] V.D. Sonkin, S.P. Levushkin, Problem of optimization of physical condition of schoolchildren through physical education, Human physiol. 35(1) (2009) 67-74.

[11] L.I. Tegako, Constitution, personality, health and character of a person. Belarus Science, Minsk, 2010, $162 \mathrm{p}$.

[12] S.N. Filippova, R.G. Fedin, Integrative anthropological study of the family crisis: Anthropology issues, iss. 14, Belarus Science, Minsk, 2019, pp. 133-150.

[13] S.N. Filippova, Yu.A. Matveev, O.V. Melkadze, "Transformation of the paradigm of physical education at universities on the basis of new principles of educational process management", Physical and health culture, 2019, no. 2, pp. 82-86. 
[14] O.G. Chorayan, E.K. Aidarkin, I.O. Chorayan, Individual-typological features of regulation and interaction of functional systems in different modes of activity: review, Valeology 2 (2001) 5-15.
[15] N.I. Schlyk, Heart rhythm and type of regulation in children, teenagers and athletes, Udmurt State Univer., Izhevsk, 2009, pp. 5-254. 